\title{
Flip/ELE ¡Cómo mola! o el acercamiento a la jerga juvenil
}

\author{
LORENA GARCÍA SAIZ \\ Instituto El Grao \\ garcia_lorsai@gva.es
}

Resumen: La propuesta trabaja la jerga juvenil con alumnado de nivel B1. Concretamente, un grupo de intercambio de estudiantado alemán de secundaria conoce esta variedad diastrática mediante actividades guiadas y una gran variedad de productos culturales -música, publicidad o medios de comunicación-, que realiza conjuntamente con alumnado nativo dentro de la materia Lengua y Literatura Castellana, por lo que la adquisición de contenidos es más significativa.

Finalmente, el alumnado de E/LE junto con el estudiantado nativo elabora un producto final, consistente en adaptar un cuento del Conde Lucanor -una obra medieval que sigue transmitiendo valores universales aún presentes actualmente- a formato cómic donde deben usar la jerga juvenil.

Palabras clave: jerga juvenil, producto cultural, aprendizaje significativo.

\section{Go crazy for E/LE. How cool! Or an approximation to youth language}

Abstract: The proposal works youth language with students of level B1. Specifically, a high school German students exchange group knows this diastratica variety through guided activities and a great variety of cultural products -such us music, advertising or media-, which does together with native students within language and Spanish Literature issue, so the acquisition of content is more significant.

Finally, the E/LE students with their native schoolmates draw up a final product consisting of adapting a story of Conde Lucanor -a medieval work that continues to transmit universal values nowadays- to comic book format where they must use the youth language.

Keywords: youth language, cultural product, meaningful learning.

\section{Marco teórico}

Una de las principales motivaciones de los estudiantes de E/LE es comunicarse de manera satisfactoria -en mayor o menor medida, según su nivel de conocimiento y práctica- con los nativos de la lengua de estudio. En el caso de los y las jóvenes, este interés se puede ver incrementado si se trabajan aspectos más específicos de este colectivo como es la jerga juvenil, lo que ayudará a que el intercambio con su grupo de iguales sea más efectivo y significativo si cabe. Así, el artículo aborda el acercamiento y uso de la jerga juvenil a través de una unidad didáctica dirigida a alumnado de $\mathrm{E} / \mathrm{LE}$ proveniente de un grupo de intercambio con un centro de secundaria. Tras una serie de actividades guiadas a través del análisis de diversos productos culturales, se completa este aprendizaje mediante la representación de situaciones 
comunicativas, por un lado, y la reescritura de los exempla ${ }^{1}$ del Conde Lucanor a jerga juvenil en formato cómic, por el otro lado.

Rodríguez González define el lenguaje de la jerga juvenil como un «conjunto de rasgos lingüísticos presentes en las manifestaciones lingüísticas de los jóvenes, producidas de forma oral (o por escrito, como reflejo de lo oral), en situaciones coloquiales informales» (2002:68) y se cataloga teniendo en encuentra la variedad diastrática -concretamente, la edad- y la diafásica, en relación al uso y contexto donde se produce. Pero se ha de tener en cuenta que, junto con la edad, hay otros factores sociales como el sexo, nivel cultural, clase social o grupos específicos entre otros, que se entrecruzan en el lenguaje juvenil, por lo que no se puede clasificar como homogéneo. Asimismo, tampoco hay que olvidar los factores diatópicos, que muestran también diversidad dentro de la jerga juvenil.

Por tanto, bajo la apariencia clara y unívoca de lenguaje juvenil «subyace una pluralidad de variedades juveniles, debidas a la existencia de factores sociales, culturales y geográficos, concomitantes con el factor edad que actúa como rasgo unificador» (Herrero Moreno 2002: 69).

El lenguaje juvenil se caracteriza en los niveles fónico, morfosintáctico y especialmente en el léxico como jerga con la que los jóvenes marcan su posición ante la cultura oficial mediante un argot propio que identifica a sus componentes y los cohesiona socialmente, además de definir y particularizar a sus miembros como parte integrante el grupo. Para ello, hacen uso de un estilo informal -que se identifica como el coloquial- en el que el objetivo es estrechar lazos ente los jóvenes y relacionarse, por lo que se fuerza el contexto social y la comunicación fáctica. Así, los temas tratados son propios del ámbito cotidiano dentro de las actividades, vivencias e intereses juveniles, tales como los estudios, las relaciones personales y afectivas, el ocio, el trabajo, la música o la bebida, entre otros, haciendo uso principalmente de la comunicación oral.

Es por ello que la jerga juvenil entra dentro del llamado español coloquial, que Vigara Tauste (1980: 13) define como

conjunto de usos lingüísticos registrables entre dos o más hispanohablantes, conscientes de la competencia de su interlocutor o interlocutores, en una situación normal de la vida cotidiana, con utilización de los recursos paralingüísticos y extralingüísticos aceptados y entendidos, pero no necesariamente compartidos por la comunidad en que se producen.

A nivel sintáctico se aprecia, junto con los enunciados oracionales, otro tipo de construcciones más propias en el lenguaje juvenil tales como los enunciados interjectivos, frases nominales y los enunciados suspendidos (Herrero Moreno 2002).

Junto con lo anteriormente citado, la inserción de elementos disfemísticos en estructuras de la lengua estándar -con la que se busca transgredir y que alteran notablemente la configuración estructural de los sintagmas, además del cambio de estructuras sintácticas -a partir de un uso diferente de los verbos que forman parte de ellas, son los dos fenómenos sintácticos más representativos en el lenguaje juvenil.

La juventud usa el disfemismo porque apuesta por formas que se apartan de la norma especialmente las más estigmatizadas, tales como los vulgarismos, y expresiones y palabras

\footnotetext{
${ }^{1}$ Los exempla son cuentos o fábulas con función moralizadora o doctrinal que se hicieron populares en España a partir del siglo XIII. El Conde Lucanor -escrito por el infante Don Juan Manuel y formado por cincuenta y una narraciones breves- es del siglo XIV, ya que está escrito entre 1330 y 1335.
} 
informales de connotación baja y de gran carga expresiva-, lo que suele aportar un tono humorístico y peyorativo al discurso, como reacción a la solemnidad y rigidez del lenguaje oficial, especialmente de los medios de comunicación.

Respecto al cambio de estructuras sintácticas por parte de la juventud, Herrero Moreno recuerda que «en el sociolecto juvenil se encuentran verbos que han adquirido un nuevo significado, intencionadamente creado o modificado por el grupo, lo que, en consecuencia, contribuye a la formación de estructuras diferentes que se convierten en expresiones muy idiomáticas» (2002: 94).

Además, los medios que usan este antilenguaje para dotarse de expresividad son la transferencia o cambio semántico, el cambio de código y el cambio de registro. Y es que la juventud tiene una postura contracultural, rechaza el sistema y trata de subvertirlo usando el elemento lingüístico, entre otros, por lo que desfigura sus códigos principalmente mediante la deformación de significante por medio de la mutilación o alteración de morfología y el establecimiento de una nueva relación entre significante y significado, lo que genera una polisemia que puede ser ajena al mundo adulto o extraño al grupo (Rodríguez González 2002).

Por tanto, se entiende el lenguaje juvenil como reacción a lo citado anteriormente -haciendo uso de un idioma más desinhibido, materialista, degradado y contundente (Casado Velarde 2002)-, frente al discurso oficial anónimo, impersonal y frío y con un lenguaje abstracto, altamente tecnificado y eufemístico, practicado por los políticos. Además, como se recoge en la unidad que se presenta en este artículo al observar la relación e influencia entre la jerga juvenil y los productos culturales, y tal y como también subraya Herrero Moreno (2002: 71), la importancia de este tipo de lenguaje

estriba en la proyección posterior que ha logrado y puede seguir logrando, al incorporar a la lengua común elementos morfosintácticos y, sobre todo, léxicos, anteriormente considerados como privativos del grupo que han obtenido de esta forma una notable difusión y amplitud de uso, lo que pone de manifiesto su contribución a los cambios lingüísticos acaecidos mediante el paso de elementos del sociolecto al registro informal, y de éste al estándar.

El argot juvenil conecta con la comunicación oral popular, por lo que está condicionado por los factores psicolingüístico, sociolingüístico y puramente lingüístico, que imponen una determinada forma de expresión y una forma de contenido, tal y como lo recoge Hernández Alonso (1991).

Entre los factores psicolingüísticos se destaca una afectividad muy acusada, espontaneidad comunicativa, improvisación, y la superposición y potenciación de códigos diferentes, tales como el verbal o el cinésico. En el plano sociolingüístico es clave el tipo de relación entre los hablantes, la situación psíquica de los mismos y la intención que lleva el mensaje, que se caracteriza por la cercanía y la empatía. En el puramente lingüístico se debe tener en cuenta la ley del "mínimo esfuerzo", es decir, una tendencia a la economía lingüística debido a la actitud relajada de los interlocutores, que los lleva a una economía lingüística, si bien esto contrasta en otras ocasiones con la repetición o las paráfrasis alrededor de una simple idea. Por otra parte, en este tipo de comunicación el receptor tiene un papel fundamental, ya que se le intenta impresionar, ganar su atención e interés. Así, el emisor intenta dominar la situación y reforzar su pertenencia en su grupo de iguales (Hernández Alonso 1991). Concretamente, en la comunicación oral coloquial destacan los elementos con función expresiva, conativa y fática, que envuelven a los de función representativa, anulan prácticamente a la metalingüística y apenas comparten con rasgos de función poética. 
De acuerdo al Plan Curricular del Instituto Cervantes (PCIC), esta unidad didáctica trabaja de manera general los referentes culturales, los saberes y comportamientos socioculturales y las habilidades y actitudes interculturales. Por otro lado, los contenidos que trata -dirigidos a alumnado del tercer curso de Educación Secundario Obligatoria (ESO) - se ubican dentro de la Ley Orgánica 8/2013, de 9 de diciembre, para la mejora de la calidad educativa (LOMCE) en el apartado Conocimientos de la lengua; habla sobre las variedades de la lengua y establece como objetivo conocer "los diferentes registros y factores que inciden en el uso de la lengua en distintos ámbitos sociales y valoración de la importancia de utilizar el registro adecuado según las condiciones de la situación comunicativa» (2013).

Los objetivos generales de esta unidad didáctica se centran en desarrollar la compresión y expresión oral y escrita acorde al contexto comunicativo, argumentar de manera clara y concisa, promover la tolerancia y desarrollar la conciencia crítica. - Los objetivos específicos son reconocer y usar expresiones de la jerga juvenil y apreciar el valor de la narrativa y los productos culturales como difusores del idioma en sus diversas variedades diastráticas.

En cuanto a las competencias generales, se abordan el conocimiento sociocultural, la consciencia intercultural y la competencia existencial. Respecto a las competencias comunicativas de la lengua, se tratan principalmente la lingüística (léxica y semántica), sociolingüística y pragmática.

La metodología de trabajo que se aplica en el desarrollo de la unidad didáctica -conformada por el alumnado nativo y la docente de Lengua y Literatura Castellana- es por parejas y pequeños grupos, y posterior puesta en común en gran grupo, de modo que se interrelacionan en todo momento el estudiantado de E/LE con el de acogida. Además, se trabajan las destrezas de la compresión y expresión oral y escrita, la interacción y la mediación.

En cuanto a la evaluación, los criterios que se deben tener en cuenta son la observación diaria del docente hacia el alumnado, ya que es clave mientras realiza actividades para consolidar los contenidos. Finalmente, hay una evaluación por parte del enseñante tanto de la situación comunicativa que las parejas representan como del producto final -el cómic con jerga juvenil de un cuento del Conde Lucanor-, a la que se añade una coevaluación entre el alumnado, todo ello mediante el uso de rúbricas. Los aspectos que se valoran son el vocabulario y las colocaciones usadas, el dominio del contenido y las estructuras tratadas, la organización del texto, el trabajo cooperativo y la interacción.

\section{Desarrollo de la unidad didáctica}

El desarrollo de esta unidad, centrada en la jerga juvenil, surgió como propuesta del alumnado local de un aula -compuesta, a nivel general, por estudiantado de nivel B2 con buenos hábitos de trabajo y resultados académicos- para trabajar de manera conjunta con sus homólogos alemanes que estaban de intercambio en el centro. Consideraban que trabajar este lenguaje específico facilitaría un mayor acercamiento al contexto comunicativo y la realidad en la que estos se iban a mover, tanto dentro como fuera de la clase, ya que se contaba con actividades extraescolares incluidas en el intercambio.

Hay que destacar que el estudiantado de E/LE contaba con un nivel B1 y un amplio porcentaje del mismo no había participado nunca en una actividad de intercambio con nativos de español, lo que hacía que esta iniciativa sobre la jerga juvenil, junto con la propia estancia fuera de su país de origen fuera altamente significativa para poder practicar el castellano. 
Para elaborar la propuesta didáctica se realizó un trabajo cooperativo, donde las actividades fueron desarrolladas por la docente y los contenidos se crearon entre el alumnado local y la docente, mediante las sugerencias de los primeros y las orientaciones de la segunda.

De este modo, se apostó por acercar la jerga juvenil mediante diversos soportes culturales, la recogida de dichas expresiones en vocabularios individuales y la puesta en práctica de las expresiones usadas, estudiadas y recogidas. Este último aspecto se trabajó de forma oral -con la producción en el aula de situaciones comunicativas y, fuera de ella, en las actividades extraescolares- y, por otro lado, de manera oral, con la comprensión, resumen y transcripción haciendo uso de la jerga juvenil de cuentos medievales seleccionados del Conde Lucanor. Así, el alumnado de E/LE comprobó los usos de la jerga juvenil y los contextos donde se aplican, además de ver que procedimientos se llevan a cabo para la creación de nuevos vocablos o transformaciones semánticas, léxicas y sintácticas.

En la primera sesión se inició con una lluvia de ideas sobre lo que creían que era la jerga juvenil y por qué se creó, en la que se recogieron expresiones típicas acompañado de un vídeo introductorio $^{2}$. Posteriormente, y por parejas mixtas (alumnado local y de E/LE), debían ubicar un listado de expresiones de la jerga juvenil en su correspondiente campo léxico. Concretamente, situaban en las áreas de estudio, ocio, relaciones interpersonales, relaciones afectivo-sexuales, partes el cuerpo, carácter de las personas, estado anímico-mental, valoración de objetos, situaciones y vida cotidiana las siguientes expresiones:

(1) Ser un bocas, palmar, piltra, tener un polvo, estar hasta la bola, calentar la silla, ser un tostón, morro, salir de fiesta, napia, pavo, fugarse, garito/bareto, amuermarse, pasarlo de puta madre, dar un pico, cabolo, llevar una buena tajada, planchar la oreja, tronco, ser un pardillo, irse la olla, guay, chungo

Posteriormente, buscaban sinónimos de las expresiones clasificadas en la actividad anterior ${ }^{3}$ :

(2) Ser un bocas: ser un chivato, bocachanclas

(3) Palmar: estirar la pata, morir

(4) Piltra: sobre, cama

En la segunda sesión, también por parejas mixtas, debían averiguar cuál había sido el proceso de formación de un conjunto de palabras, teniendo como referentes una serie de ejemplos que se aprecian en la tabla 1.

(5) Estar colgado, finde, porreta, hermano, segurata, abrir(se), bocas, viejo, pringao, fiestuki, taladrar, ¿tas loco?

\begin{tabular}{|l|l|}
\hline PROCESOS DE CREACIÓN & EJEMPLOS \\
\hline Cambio semántico & tío \\
\hline $\begin{array}{l}\text { Cambios morfológicos con uso de } \\
\text { sufijos como } \\
\text { ata, -ote, -eta,... }\end{array}$ & machote \\
\hline Acortamientos & tranqui \\
\hline Deformaciones léxicas & ¿qué paisa? \\
\hline
\end{tabular}

Tabla 1. Cuadro donde situar las palabras a trabajar del ejemplo (5)

\footnotetext{
${ }^{2}$ El vídeo se encuentra disponible en el siguiente enlace: https://www.youtube.com/watch?v=D7nUkRj2UOo
}

${ }^{3}$ Para esta actividad se ha puesto como ejemplo sólo las tres primeras palabras que aparecen en la lista (1) 
Más tarde, debían localizar expresiones de la jerga juvenil que aparecían en un listado de anuncios fijos, explicar su significado y señalar cómo se había realizado el proceso de formación de dichas expresiones. Como modelo está la imagen $1^{4}$.

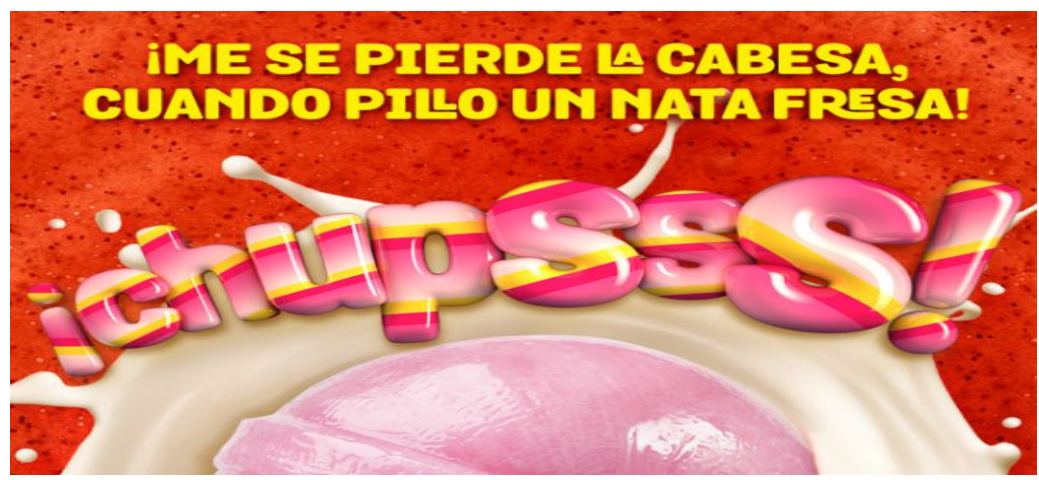

Imagen 1. Imagen de una campaña de publicidad estática de Chupa Chups

(6) Anuncio de Chupa Chups. Expresiones usadas: se me, cabeza, cuando pillo

La dinámica de localización de jerga juvenil, explicación semántica de la misma y análisis de su proceso formativo, junto con la misma metodología de parejas, se repitió en la tercera y cuarta sesión con otros productos culturales, tales como la publicidad televisiva y los tráileres de películas:

(7) Anuncio de cereales Choco Flakes ${ }^{5}$ (expresión usada: Lo vas a flipar)

(8) Anuncio de la plataforma musical en internet Spotify ${ }^{6}$ (expresión usada: Que no te corten el rollo)

(9) Anuncio de mayonesa Ligeresa ${ }^{7}$ (expresiones usadas: Comerse la vida, comerse un yogurín)

(10) Tráiler de la película "Primos" (expresión usada: Vivir con una tía petarda que te iba a dejar tirado)

(11) Tráiler de la película "Pagafantas" (expresiones usadas: Creo que he pillado; abrazo del koala; ser un pagafantas)

(12) Tráiler de la película "Historias del Kronen"10 (expresiones usadas: Seguir mareándola; me voy a currar tronco; ¿Qué pasa?- ya ves, por aquí; tienes ahí a los colegas)

Tras el visionado de varios anuncios y extractos de películas, el alumnado nativo y el de E/LE observaba el uso de las expresiones juveniles más allá de contenidos dirigidos específicamente a la juventud, ya que se extendía a otras franjas más adultas. Esto muestra como los medios de

\footnotetext{
${ }^{4}$ Este anuncio ha sido extraído de la siguiente dirección: https:/elpais.com/elpais/2015/09/24/tentaciones/1443087662_023809.html

${ }^{5} \mathrm{https}$ //www.youtube.com/watch?v=jujU9_KMlUs

${ }^{6}$ https://www.youtube.com/watch?v=KJZW-OAvUHk8

${ }^{7} \mathrm{https}: / /$ www.youtube.com/watch? $\mathrm{v}=\mathrm{tdEdNihJzDU}$

${ }^{8} \mathrm{https}: / /$ www.youtube.com/watch?v=ZLlGC9J4dWk

${ }^{9} \mathrm{https}: / / \mathrm{www}$.youtube.com/watch?v=mli1_K0JvTs

${ }^{10} \mathrm{https}: / / \mathrm{www}$.youtube.com/watch? $\mathrm{v}=\mathrm{X}$ jZZHkOYSIg
} 
comunicación están usando este lenguaje tan creativo para captar la atención de público para el consumo de dichos productos refleja la amplia instauración del valor de la "eterna juventud" en la sociedad occidental.

La quinta sesión también abordó otro producto cultural como son las canciones. Concretamente, se centró en el estilo del trap ${ }^{11}$, ya que actualmente es un tipo de musical muy popular entre los jóvenes y que está plagado de expresiones de la jerga juvenil

(13) Canción "Cabello de ángel”, de Pimp Flaco'12 (expresiones usadas: a ti te va a molar lo que yo te diga que mola; sobre to; los raperos están rallados porque les meto fuerte; o me rayo por ti)

(14) Canción "Niño de cristal", de Natos y Waor ${ }^{13}$ (expresiones usadas: no me dejan entrar al club por las putas, y hoy me pagan pa que vaya; te comieron la tostada; mi rap es paliza disfrazá de caricia)

La dificultad en esta actividad estribó en la selección de las piezas musicales por parte del docente, ya que en muchas ocasiones el nivel de "violencia" verbal en cuanto a insultos y actitudes machistas es altamente elevado. Por ello, también fue interesante hacer esta reflexión desde una mirada crítica y coeducativa, donde hubo un debate de fondo en el que se analizaron qué valores trasmiten los productos culturales a la juventud y los efectos que pueden causar la interiorización de los mismos.

Tras la anterior actividad, cada pareja escogió una situación comunicativa de entre una serie de imágenes, sobre la que prepararon un diálogo en el que debían aparecer expresiones de la jerga juvenil. Posteriormente, lo representaron en la clase, aplicando de una manera significativa los contenidos trabajados en la unidad.

Para acabar, cada pareja realizó un producto final. Concretamente, debía escoger entre un listado de cuentos escogidos de la obra medieval El Conde Lucanor y reescribirlo por parejas en cómic -usando un total de seis viñetas- y en el que también apareciera algo de jerga juvenil. En la imagen 2 -que aparece como anexo de este artículo en su parte final-, se puede ver un ejemplo de la labor realizada con el exempla VIII, llamado Lo que sucedió a un hombre al que tenían que limpiarle el hígado. En él se puede observar la introducción de expresiones de la jerga juvenil por parte de la pareja mixta de estudiantes como:

(15) necesitar pasta, quedarse a cero, colega, chaval, eres el mejor,

Al mismo tiempo, se logró mantener la estructura clásica por la que el Conde Lucanor pide consejo a su criado Patronio y éste le contesta mediante una breve historia con sentido didáctico que siempre se cierra con una moraleja final a modo de pareado. De este modo, se comprobó cómo se podía jugar en un texto con el contexto comunicativo al hacer uso de otros significantes sin alterar los significados de los mismos y, por ende, de su mensaje.

\section{Conclusiones}

\footnotetext{
${ }^{11}$ Es una mezcla de hip hop y música electrónica de baile y se caracteriza por su letra agresiva, uso constante de subajos y percusión. Se originó en la década de 1990 en el sur de los Estados Unidos, pero ha sido en esta década cuando se ha extendido a otros idiomas como el castellano, tanto en Latinoamérica como en España. El término de "trap" viene del argot inglés que hace referencia a los lugares donde se vende droga ilegalmente y/o a la propia acción de vender la droga. Las letras de este género giran en torno a esa realidad, con vocablo relacionado con la calle, las drogas, el sexo o la violencia, entre otros, sin censuras ni eufemismos.

${ }^{12} \mathrm{https}: / /$ www.youtube.com/watch? $\mathrm{v}=\mathrm{pWrWsf4APGA}$

${ }^{13} \mathrm{https}$ ://www.youtube.com/watch?v=rTv-O-LHTI0
} 
La batería de actividades realizadas en esta unidad ayudó a asentar conocimientos sobre el uso y significado de la jerga juvenil para el alumnado de E/LE mediante un aprendizaje significativo, ya que interiorizó parte de la dinámica del uso de estas expresiones y la estructura de las mismas. Por otra parte, también sirvió para que tanto el estudiantado alemán como el nativo reflexionara sobre el constructo cultural que se refleja en dichas expresiones y que tiene que ver con los valores y actitudes frente a las normas de la sociedad. Al mismo tiempo, también se vio la influencia en los medios de comunicación y la retroalimentación que éstos generan en la sociedad al incluir en diversos productos culturales expresiones propias del lenguaje juvenil, lo que ayuda a difundir y normalizar más si cabe su uso, y a que llegue a público cada vez más variado y de mayor franja de edad. Junto con esto, también tuvo cabida el desarrollo de una mirada crítica y coeducativa.

\section{Bibliografía}

CASAdo Velarde, Manuel (2002). «Aspectos morfológicos y semánticos del lenguaje juvenil». En F. Rodríguez (ed.), El lenguaje de los jóvenes (pp. 57-66). Barcelona: Ariel.

HERnÁNDEZ Alonso, César (1991). El lenguaje coloquial juvenil. Recuperado el 22/04/18, de https://cvc.cervantes.es/ensenanza/biblioteca_ele/aepe/pdf/revista_3839_21-22_91/revista_38-39_21-22_91_03.pdf

Herrero Moreno, Gemma (2002). «Aspectos sintácticos del lenguaje juvenil». En F. Rodríguez (ed.); El lenguaje de los jóvenes (pp. 67-96). Barcelona: Ariel.

InStituto CeRvantes (2007). Plan curricular del Instituto Cervantes (PCIC). Recuperado el 30/4/18, de https://cvc.cervantes.es/Ensenanza/biblioteca_ele/plan_curricular/default.htm

Ministerio DE EDUCACIÓN (2013). Ley Orgánica 8/2013, de 9 de diciembre, para la mejora de la calidad educativa (LOMCE). Recuperado el 30/4/18, de http://www.boe.es/boe/dias/2013/12/10/pdfs/BOE-A-2013-12886.pdf

REAL ACADEMIA ESPAÑOla (2014). Diccionario de la lengua española. Recuperado el 30/04/18, de http://dle.rae.es/?w=diccionario

RODRÍGUEZ GONZÁLEZ, Félix (2002). «Lenguaje y contracultura juvenil: anatomía de una generación». En F. Rodríguez (ed.); El lenguaje de los jóvenes (pp. 29-56). Barcelona: Ariel.

Vigara Tauste, Ana Ma. (1980). Aspectos del español hablado. Madrid: Sociedad General Española de Librería. 


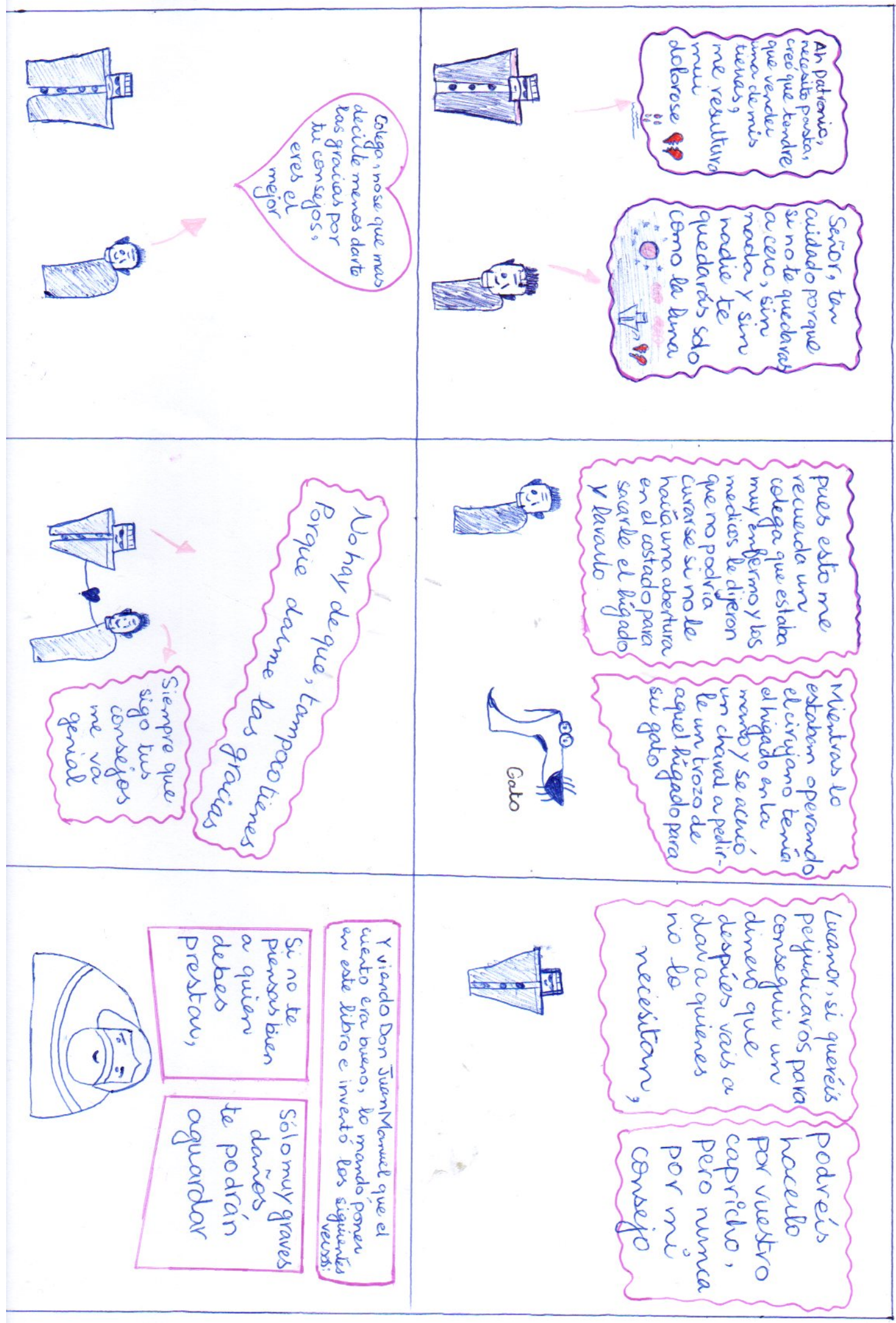

Imagen 2. Cuento VIII del Conde Lucanor en formato cómic y contado con jerga juvenil 